\title{
Mechanical and dielectric properties of epoxy/dicyclopentadiene bisphenol cyanate ester/glass fabric composites
}

\author{
J. H. Wang, G. Z. Liang*, H. X. Yan, S. B. He \\ Department of Applied Chemistry, School of Science, Northwestern Polytechnical University, Xi' an Shaanxi 710072, \\ China
}

Received 2 December 2007; accepted in revised form 29 December 2007

\begin{abstract}
The impact and flexural strengths of epoxy-dicyclopentadiene bisphenol cyanate ester (EP-DCPDCE) hybrid thermoset as well as the interlaminar shear strength (ILSS) and flexural strength of the composites consisting of the hybrid thermoset and glass fabric were studied. It is found that the addition of epoxy resin (EP-51) can improve the mechanical properties, particularly, the impact strength of DCPDCE matrix and the ILSS of glass fabric reinforced composites. The improvements of the mechanical properties were obvious when the content of EP-51 is from 15 to $30 \mathrm{wt} \%$. The investigations of the interphase of composites by scanning electron microscope (SEM) and dynamic mechanical analysis (DMA) confirm the improvement of mechanical properties of the composites. However the addition of EP-51 has negative effects on the thermal and dielectric property of the composites.
\end{abstract}

Keywords: polymer composites, cyanate ester, mechanical properties, interphase

\section{Introduction}

The necessity of developing high speed computers has led to the exploration of new materials which can expend the electrical and mechanical performance limits of the presently available technology [1-4]. In the microelectronics industry low permittivity and dissipation factor, good mechanical and thermal properties are required for intermetal dielectrics, especially in printed circuit board (PCB) industry [5].

Polycyanurates are interesting polymers for low constant and dissipation dielectrics [6-8]. In the curing reaction three cyanate ester functional groups (-OCN groups) form a triazine ring (trimerization). Due to the high degree of symmetry in the triazine ring, where dipoles associated with the carbon-nitrogen and carbon-oxygen bonds are coun- terbalanced, polycyanurates have low relative permittivity in general (e.g., $\varepsilon<3.2$ for trifunctional homopolymer networks) [9]. Dicyclopentadiene (DCPD) is a raw material for low dielectric polymers due to its low polarity and low moisture absorption. This hydrophobic nonpolar bridging group contributes to excellent moisture resistance and a dramatic reduction in the permittivity without determinately affecting thermal performance [10]. Dicyclopentadiene bisphenol cyanate ester (DCPDCE) introduces the DCPD structure into the backbone of bisphenol A cyanate ester. For the cured resin of DCPDCE, the cycloaliphatic character in the structure is effective in reducing permittivity and moisture absorption while the aromatic character maintains a high $T_{g}$ [11]. It is a potential dielectric matrix for composites. But like other 
cyanate esters, DCPDCE has high cross linkage which makes it fragile and limits its usage in some cases requiring good mechanical properties [12-14]. In this work, we used epoxy resin to modify DCPDCE and analyzed the influence of epoxy resin on the mechanical properties of neat resin and glass fabric reinforced composites.

\section{Experimental}

\subsection{Materials}

DCPDCE, containing 25\% weigh fraction of butanone, was purchased from Shangyu Shengda Biochemical Company, Ltd. (located in Zhejiang, China), with a brand name of SD-3 and cyanate equivalent 215. Epoxy resin (EP-51) was provided by Xi' an Resin Company, Ltd. (located in Shaanxi, China), with the epoxy equivalent weight of 196. E-glass fabric (areal density: $210 \pm 20 \mathrm{~g} / \mathrm{m}^{2}$, weave style: plain, yarn density: $2.55 \mathrm{~g} / \mathrm{cm}^{3}$ ) with a trademark of EW210 was supplied by Nanjing Fiber Co., (located in Nanjing China). Figure 1 gives the chemical structures of DCPDCE and EP-51.

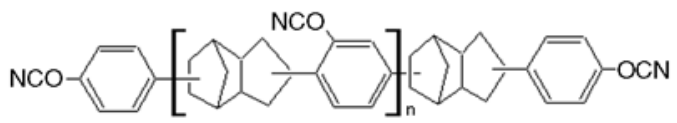

Dicyclopentadiene bisphenol cyanate ester (DCPDCE) $n=0 \sim 3$

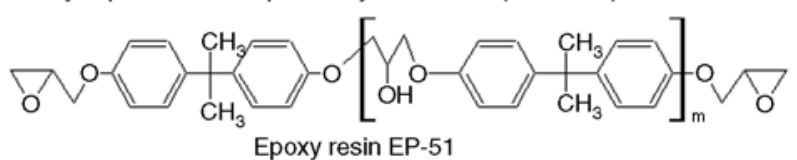

Figure 1. The chemical structures of DCPDCE and EP-51

\subsection{Preparation of cured neat resin and glass fabric composite}

The butanone in the DCPDCE was removed under vacuum at $80^{\circ} \mathrm{C}$ through distillation to obtain pure DCPDCE which was mixed with EP-51. The mixture was agitated about $5 \mathrm{~min}$ at $140^{\circ} \mathrm{C}$ until EP-51 and DCPDCE became homogeneous. The homogeneous mixture was poured into a pre-heated mould $\left(150^{\circ} \mathrm{C}\right)$ with release agent on the inner walls, and then, the mould was degassed under vacuum for $25 \mathrm{~min}$ at $140^{\circ} \mathrm{C}$, followed by the curing cycle and post-curing cycles:

Curing cycle: $170^{\circ} \mathrm{C} / 2 \mathrm{~h}+180^{\circ} \mathrm{C} / 1 \mathrm{~h}+200^{\circ} \mathrm{C} / 1 \mathrm{~h}$ Post-curing cycle: $220^{\circ} \mathrm{C} / 2 \mathrm{~h}$

Proper amount of EP-51 and about the same weight of solvent of acetone were added into the DCPDCE solution of butanone, and the mixture was agitated for about 5 min until they became homogeneous. The composites were fabricated by a hand lay up technique as follows: the above homogeneous mixture was painted on glass fabric (pre-dried at $200^{\circ} \mathrm{C}$ for $30 \mathrm{~min}$ before used) with brush, and the resulted prepreg was hung up at room temperature for at last $24 \mathrm{~h}$ to remove the solvents of acetone and butanone mostly. After that, the prepreg was cut to pieces of $300 \mathrm{~mm} \times 300 \mathrm{~mm}$, and 14 sheets of cut prepreg were piled onto the mould. The prepreg in the mould was degassed under vacuum at $140^{\circ} \mathrm{C}$ for $30 \mathrm{~min}$ to remove the remained solvents and the trapped air, and then, the mould loaded with the prepreg was put into a machine which can provide pressure and heat at the same time. The mould was heated to $160^{\circ} \mathrm{C}$ at the rate of $2^{\circ} \mathrm{C} / \mathrm{min}$ under contact pressure. Before gelation, while some silk could be drawn from the resin, a pressure of $0.7 \mathrm{MPa}$ was applied for $15 \mathrm{~min}$, and when the resin gelled, a pressure of $1.5 \mathrm{MPa}$ was applied and maintained through the following process of $180^{\circ} \mathrm{C} / 1 \mathrm{~h}+200^{\circ} \mathrm{C} / 1 \mathrm{~h}+220^{\circ} \mathrm{C} / 2 \mathrm{~h}$. The pressure was released until the mould cooled to room temperature sponteneously. Some related parameters of the laminated boards are showed in Table 1.

\subsection{Test methods and equipments}

The flexural strength and impact strength of cured neat resin were measured according to GB2570-81 standard (resembling ASTM D 790-03, rectangular specimen: $80 \mathrm{~mm} \times 15 \mathrm{~mm} \times 4 \mathrm{~mm}$, span/depth $=16$ ) and GB2571-81 standard (resembling ASTM D

Table 1. Some related parameters of the laminated boards

\begin{tabular}{|c|c|c|c|c|}
\hline $\begin{array}{c}\text { Content of EP-51 } \\
{[w t \%]}\end{array}$ & $\begin{array}{c}\text { Resin content } \\
{[w t \%]}\end{array}$ & $\begin{array}{c}\text { Density of composites } \\
{\left[\mathrm{g} / \mathrm{cm}^{3}\right]}\end{array}$ & $\begin{array}{c}\text { Density of fiber } \\
{\left[\mathrm{g} / \mathrm{cm}^{3}\right]}\end{array}$ & $\begin{array}{c}\text { Fabric content } \\
\text { [\% volume] }\end{array}$ \\
\hline 0 & 37.6 & 1.75 & 2.55 & 42.8 \\
\hline 5 & 41.2 & 1.68 & 2.55 & 38.7 \\
\hline 15 & 37.1 & 1.73 & 2.55 & 42.7 \\
\hline 30 & 38.7 & 1.71 & 2.55 & 41.1 \\
\hline 50 & 40.3 & 1.70 & 2.55 & 39.8 \\
\hline
\end{tabular}


256-97, rectangular specimen: $15 \mathrm{~mm} \times 10 \mathrm{~mm} \times$ $4 \mathrm{~mm}$, unnotched) of China, respectively. The flexural strength and the interlaminar shear strengths (ILSS) of the glass fabric reinforced composite were measured according to GB/T1449-83 standard (resembling ASTM D 790-03, rectangular specimen: $60 \mathrm{~mm} \times 15 \mathrm{~mm} \times 2.5 \mathrm{~mm}$, span $/$ depth $=$ 16), and GB/T3357-82 standard (resembling ASTM D 2344, rectangular specimen: $20 \mathrm{~mm} \times$ $6 \mathrm{~mm} \times 2.5 \mathrm{~mm}$, span/depth $=5$ ) of China, respectively. The content of resin and the content of glass fabric in composites were measured according to GB/T2577-05 standard of China.

Dynamic mechanical analysis (DMA) of the composite was performed with a TA Instrument (DMA Q800) at a frequency of $3 \mathrm{~Hz}$ and a heating rate of $3^{\circ} \mathrm{C} / \mathrm{min}$, and the testing mode was single cantilever. The morphology of the fracture of cured neat resins and composites was investigated by a scanning electron microscope (SEM, Quanta 200, FEI), scanning voltage was $15 \mathrm{kV}$. The permittivity and dissipation factor were tested on AS2853 impedance analyzer at $25^{\circ} \mathrm{C}$.

\section{Results and discussions}

\subsection{The mechanical properties of cured resins}

Flexural strength and impact strength of various cured neat resins are represented in Figure 2. The curves of flexural strength and impact strength versus the content of EP-51 show approximately the same trend with the increase of EP-51 weight fraction. The flexural strength increased from 96.2 $\mathrm{MPa}$ of the pure DCPDCE resin to the peak at $120.3 \mathrm{MPa}$ at $15 \mathrm{wt} \%$ of EP-51, increasing by $25 \%$, and the

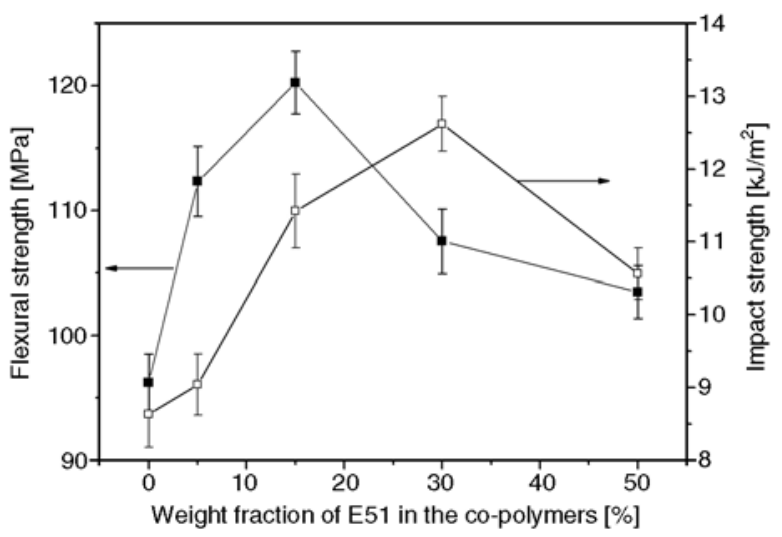

Figure 2. Flexural and impact strengths of various EP-51/DCPDCE hybrid thermosets

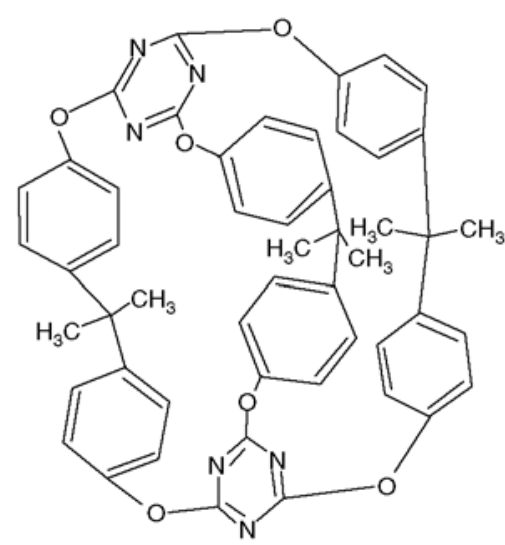

Figure 3. The cage compounds

impact strength increased from $8.63 \mathrm{~kJ} / \mathrm{m}^{2}$ of the pure DCPDCE resin to the maximum value of $12.62 \mathrm{~kJ} / \mathrm{m}^{2}$ at $30 \mathrm{wt} \%$ of EP-51, increasing by $46 \%$. These results are explained as follows: firstly, the trimerization of pure cyanate ester results in high crosslink density of cyanurate network. Secondly, the presence of some non-network-buinding cage compounds (Figure 3 ) in cured cyanate ester resin and the decyanation of them contribute to defects in the cured resin $[15,16]$. Both the high crosslink density and the defects weaken the mechanical properties of self-polymerized DCPDCE resin. The addition of EP-51 could reduce the crosslink density and repair the defects through coreaction with DCPDCE (Figure 4) [17], which improve the mechanical properties of cured DCPDCE resin. However, the oxazolidinone rings forming in the co-reaction have lower mechanical properties than traizine rings, which make the mechanical properties drop from the maximum values. Figure 5 gives the morphology of fracture surface of impact samples. An obviously brittle fracture is shown for the pure DCPDCE resin (Figure 5a). On contrast, when the content of EP-51 is $30 \mathrm{wt} \%$, there are a lot of tough whorls which indicate a tough fracture (Figure 5b). These SEM micrographs prove the above analysis of the mechanical properties partially.

Figure 6 shows the storage moduli of neat cured resins. It indicates that when the content of EP-51 is 30 or $15 \mathrm{wt} \%$ the glassy storage modulus of the cured resin is higher than that of the pure DCPDCE resin. While when the temperature increases, the higher the content of EP-51 is, the faster the storage modulus decreases, which confirms the reduction 


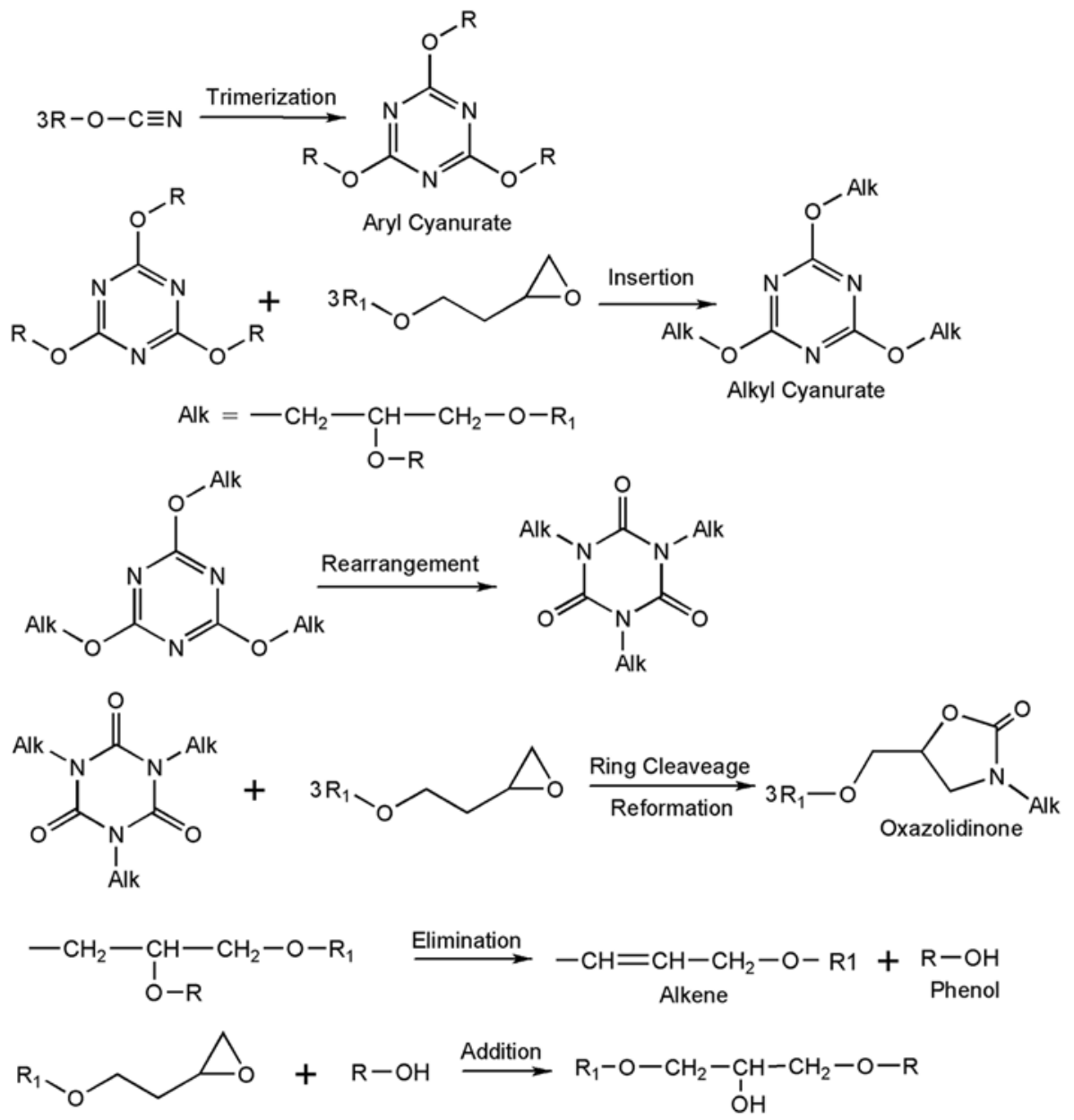

Figure 4. Reaction scheme for the co-reaction of cyanates with epoxies
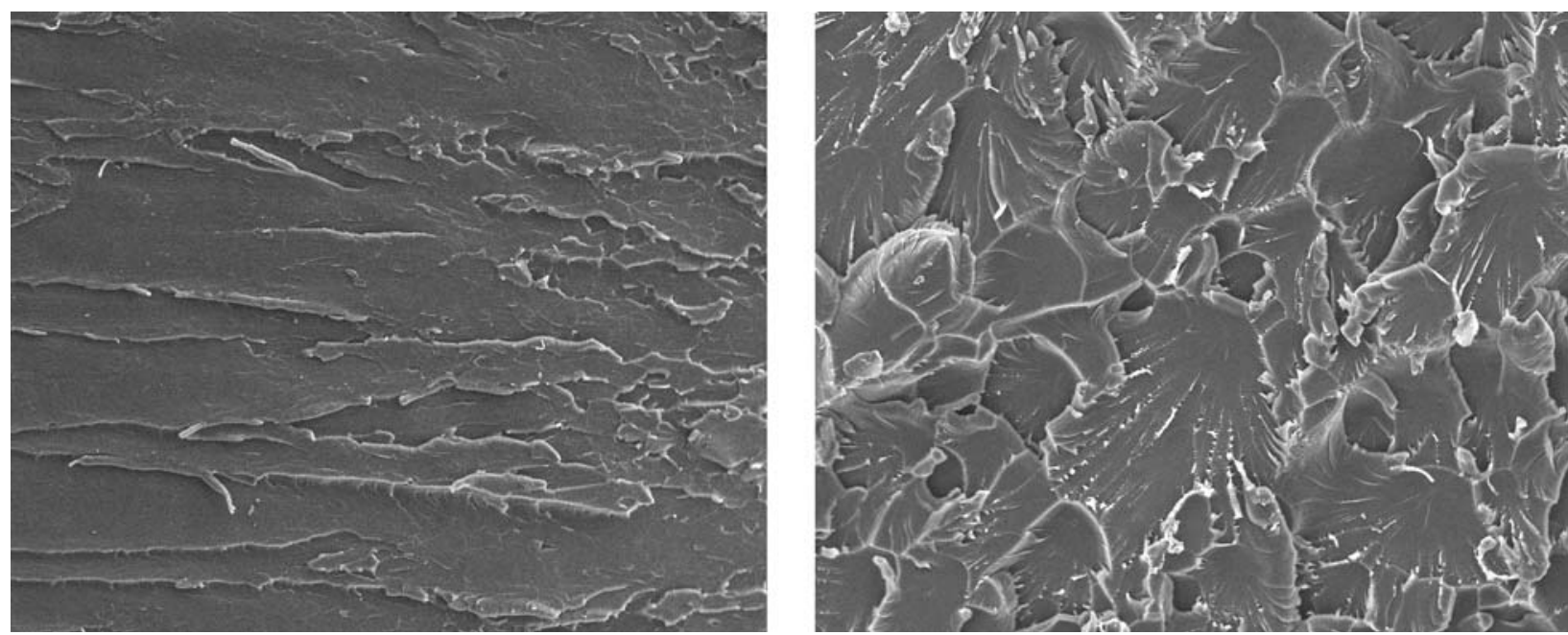

Figure 5. The morphology of the fracture surface of impact samples: (a) Pure DCPDCE, (b) EP-51/DCPDCE (30/70 by weight) hybrid thermoset

of the crosslink density in EP-DCPDCE hybrid thermoset.

\subsection{The mechanical properties of glass fabric reinforced composites}

ILSS mainly depends on the interfacial adhesion between fibers and matrix. If the adhesion between 


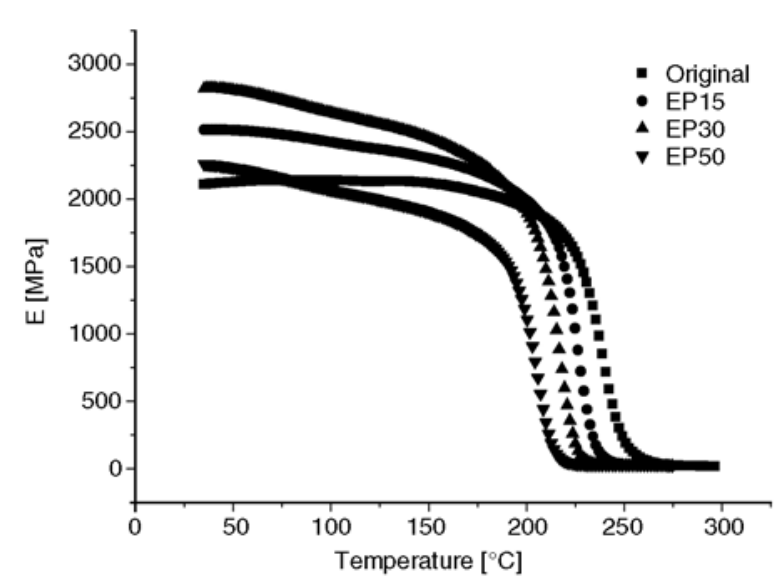

Figure 6. The storage modulus of neat resin

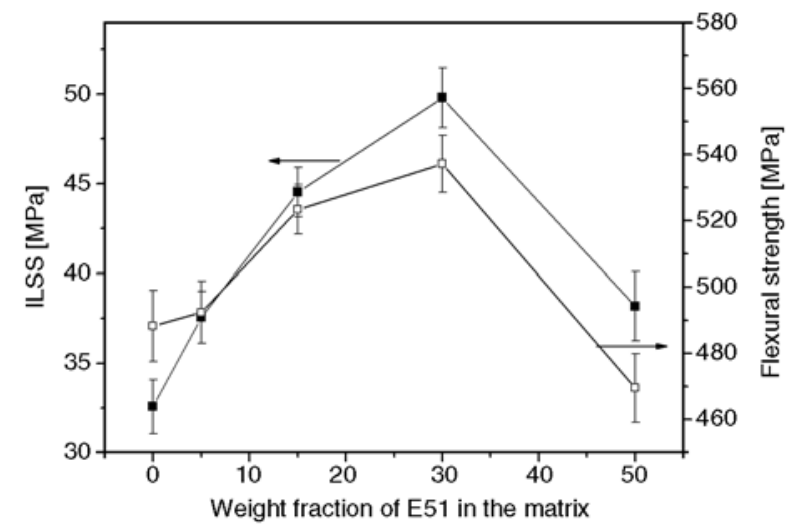

Figure 7. ILSS and flexural strength of glass fabric reinforced composites

fibers and matrix is strong enough, the mechanical property of the matrix has also influence on ILSS. Figure 7 shows the ILSS and flexural strength of the glass fabric reinforced composites versus EP-51 content in the matrix. At first, the ILSS increased with the content of EP-51 and when the content of EP-51 was $30 \mathrm{wt} \%$ the ILSS reached its maximum value, after that, the ILSS dropped from the maximum. These changes have their reasons. When DCPDCE cures, the -OCN groups take part in the trimerization reaction to form trimerization structure with very high crosslink density. The fragile nature of the trimerzation structure will result in premature failure in the interphase of the composites. When epoxy resin is added, the EP-51 can react with the triazine ring to form oxazolidinone structure which has higher polarity than trizaine ring and more probability to react and/or interact with glass fibers. Moreover, the decrease of the crosslink density improves the toughness of the matrix, which can release the residual strain forming in the processing of composite and stop microc- rack propagating more effectively. All these effects reinforce the interfacial adhesion between the matrix and glass fibers, resulting in the increase of ILSS by $48 \%$, from 32.6 to $48.2 \mathrm{MPa}$. Meanwhile the reason of the value of ILSS dropping from the maximum when the content of EP-51 is $50 \mathrm{wt} \%$ is not very clear. We surmise that the preferential adsorption of glass fibers to EP-51 makes the content of EP-51 in the interphase bigger than that in the bulk matrix and some EP-51 in the interphase can not cure completely under this curing cycle, which weakens the mechanical property of the interphase and reduces the value of ILSS.

Figure 7 also shows that the curve of flexural strength of the composites versus EP-51 content has similar trend with that of ILSS. It indicates that the stronger interfacial adhesion improves the transfer of load from matrix to fibers, consequently, enhancing the flexural strength of the composites.

\subsection{The SEM analyses of the composites}

The SEM micrograph of the fracture surface of samples after short-beam shear test can directly show whether the interfacial adhesion between the matrix and the fibers is good or not. Figure 8 gives the SEM micrographs of the fracture surface after short-beam shear test. Figure $8 \mathrm{a}$ is the micrograph of the original DCPDCE/glass fabric composite, and Figure $8 \mathrm{~b}$ is the composite which has $30 \mathrm{wt} \%$ of EP-51 in the matrix. In Figure 8a, the fiber surface of the fracture samples is smooth and little resin adheres on the fibers, which indicates weak interfacial adhesion between the resin and the fibers. In contrast, an obvious resin coat covers the fibers tightly for the Epoxy/DCPDCE/glass fabric composite in Figure 8b. This resin coat illustrates that the fracture happens in the matrix instead of on the surface of fibers.

\subsection{Dynamic mechanical analysis of the composites}

Among numerous techniques for interface characterization, DMA has attracted ever more attention because it provides a sensitive and nondestructive detection of the interphase [18-20]. DMA detects the molecular motions through measuring two types of response to a low strain periodic deformation, an elastic (stiffness) term and a damping 


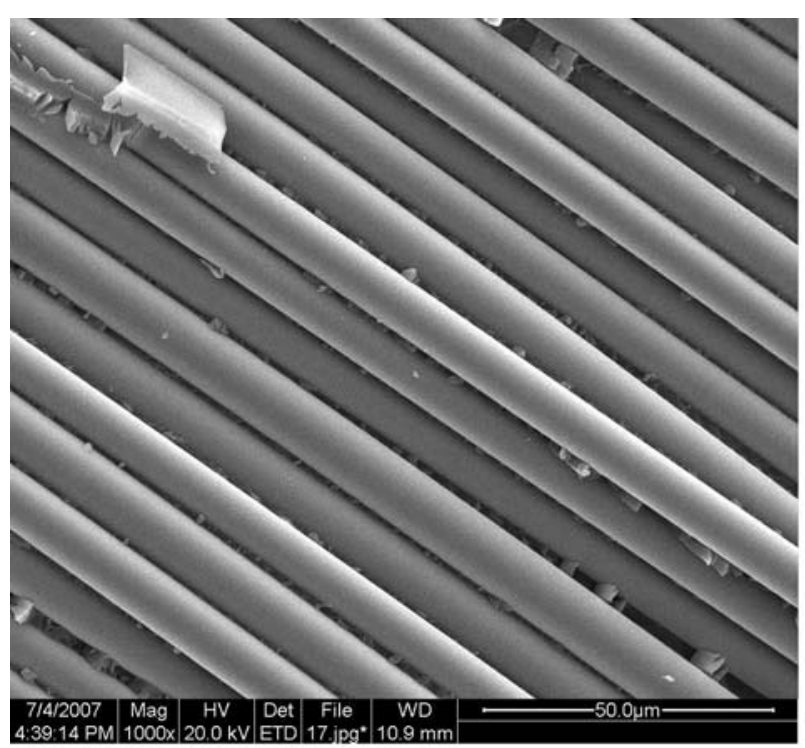

a)

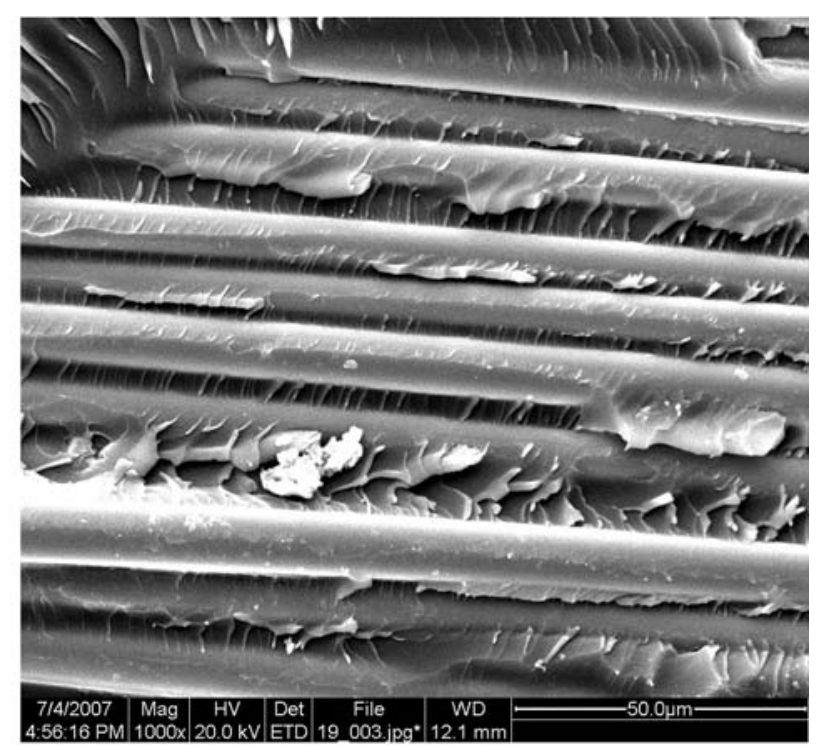

b)

Figure 8. The SEM micrograph of the fracture surface of samples after short beam shear test: (a) Pure DCPDCE/glass fabric composite; (b) EP-51/DCPDCE (30/70 by weight)/glass fabric composite

Table 2. The values of relative parameters and the calculated parameter B

\begin{tabular}{|l|c|c|c|c|c|}
\hline \multicolumn{1}{|c|}{ System } & $\tan _{\boldsymbol{m}}$ & $\boldsymbol{t a n}_{\boldsymbol{c}_{\mathbf{c}}}$ & $\boldsymbol{\phi}_{\mathbf{f}}$ & ILSS & B \\
\hline F/EP0/DCPDCE & 0.761 & 0.285 & 0.428 & 32.57 & 1.46 \\
\hline F/EP15/DCPDCE & 0.888 & 0.275 & 0.427 & 44.52 & 1.61 \\
\hline F/EP30/DCPDCE & 0.879 & 0.239 & 0.411 & 49.80 & 1.77 \\
\hline F/EP50/DCPDCE & 0.738 & 0.296 & 0.398 & 38.17 & 1.50 \\
\hline
\end{tabular}

(energy dissipation) term, and the damping is a sensitive indicator of all kinds of molecular motions that are going on in a material. In composite, the molecular motions at the interphase contribute to the damping of the material. In summary, the damping of a composite depends greatly on the interfacial interactions. So we employed DMA and a parameter proposed by former researchers to investigate the interphase further.

The parameter $B$ which was first introduced by Ziegel is described by Equation (1):

$\tan \delta_{c}=\left(1-B \phi_{f}\right) \cdot \tan \delta_{m}$

The stronger the interfacial interaction is, the higher the value of parameter $B$ [21]. Among many research works, parameter $B$ which corrects the volume fraction of reinforcement because of the formation of a layer of immobilized interphase resulting from strong interactions at the interface is the particularly worth mentioning one conducted by Dong and Gauvin [22]. Therefore, we chose the parameter $B$ to evaluate the interfacial adhesion between the fibers and matrix.
Table 2 gives the values of some relative parameters and the parameter $B$ of the composites, in which $F$ refers to fabric and $\mathrm{EP}_{i}$ stands for the matrix has $i$ wt\% of EP-51. A good relationship between the parameter $B$ and the ILSS of the composite is found, that is, the higher parameter $B$ is, the higher ILSS of composites will be.

Figure 9 shows the curves of DMA of the composites. From Figure 9a, we can see that the composites containing $30 \mathrm{wt} \%$ of EP-51 in the matrix has a higher storage modulus since the improvement of interfacial adhesion, while the thermal stabilities of the composites containing EP-51 decline for the poorer thermal property of oxazolidinone structure in the matrix.

\subsection{The dielectric property of the composites}

In order to understand the influence of epoxy resin on the dielectric property of the composites, the permittivity and dissipation factor of the composites were investigated. Figure 10a gives the changing of the permittivity and dissipation factor versus content of EP-51. It indicates that the addition of EP-51 has negative effect on the dielectric property 

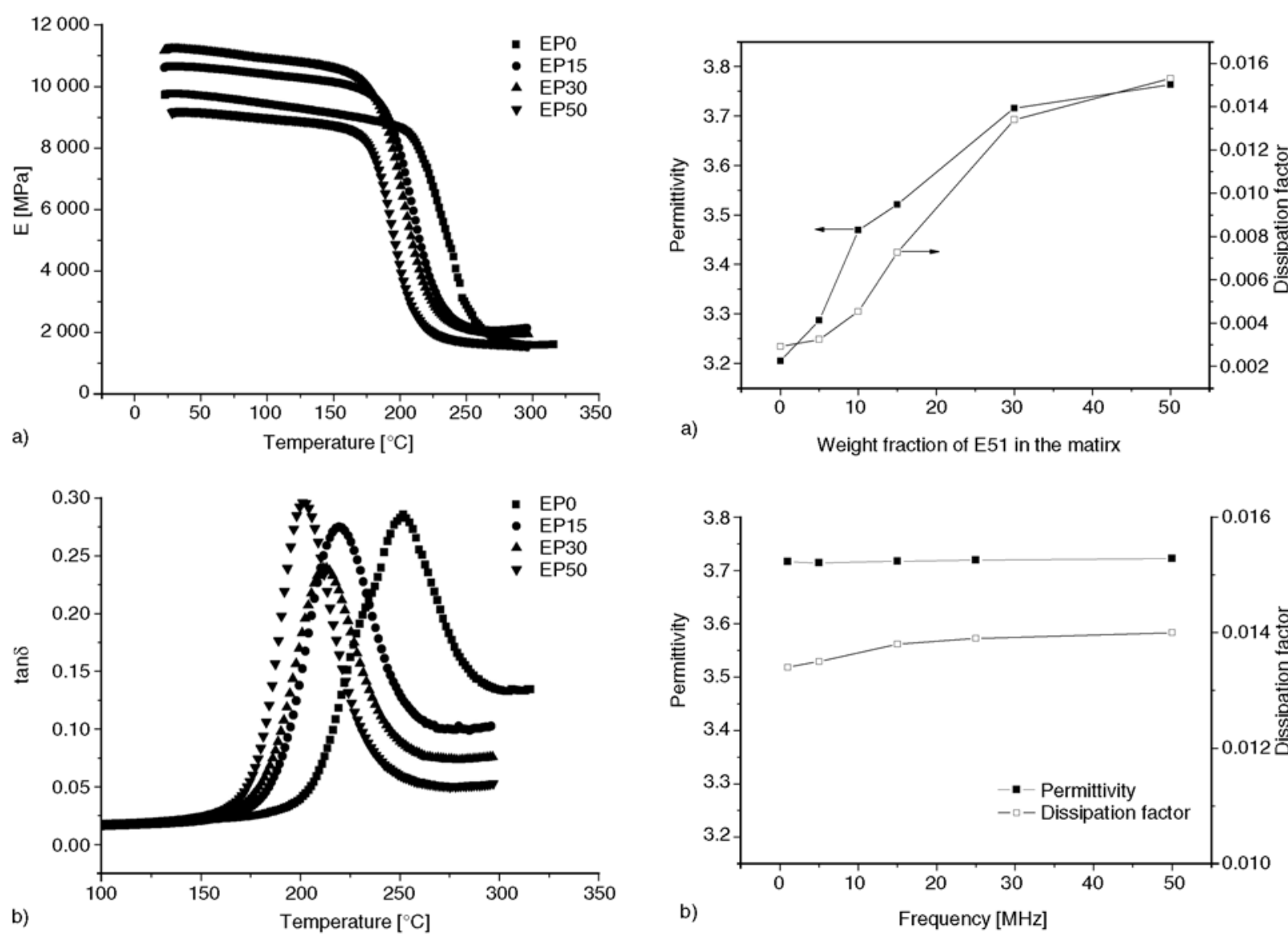

Figure 9. The DMA curves of the composites: (a) the comparison of storage modulus (b) the comparison of $\tan \delta$

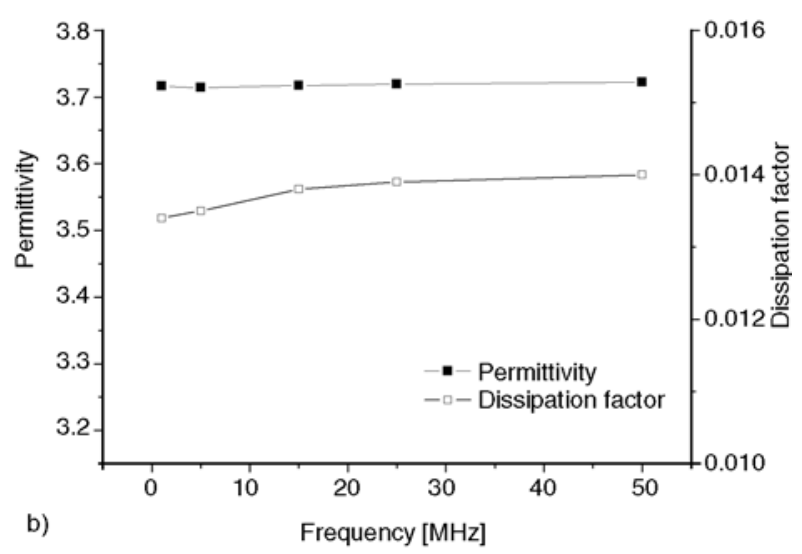

Figure 10. The dielectric property of the composites:

(a) at the frequency of $1 \mathrm{MHz}$ (b) in a boarder frequency rang

of the composites due to the bigger polarity of oxazolidinone structure. However, when the content of EP-51 is small the influence is not significant and when the content of EP-51 is over $30 \mathrm{wt} \%$ the increasing rates of permittivity and dissipation factor slow down. Figure 10b shows the influence of frequency on the dielectric property of the composite containing $30 \mathrm{wt} \%$ of EP-51 in the matrix. From this figure we can find that the influence of frequency on the permittivity and dissipation factor of the composites is small.

\section{Conclusions}

EP-51 can improve the flexural and impact strengths of DCPDCE because of the repairing of defects and the reducing of crosslink density of the cured resin. The ILSS of the fabric reinforced composites is enhanced resulted from the improvement of toughness of the matrix and the formation of polar structure of oxazolidinone which adheres to the fibers more easily. The enhancement of the

interfacial adhesion hampers the microcrack propagating along the fiber/matrix interface. When the content of EP-51 in the matrix is $15 \sim 30 \mathrm{wt} \%$, the improvements of the mechanical properties of the matrix and the composites are bigger than other range of EP-51 content.

The addition of EP-51 has negative effects on the thermal and dielectric property of the composites and the influence of frequency on the permittivity and dissipation factor of the composites is small.

\section{Acknowledgements}

This work was supported by a grant from the Ph.D. Programs Foundation of Ministry of Education of China (No. 20050699034).

\section{References}

[1] Kuntman A., Kuntman H.: A study on dielectric properties of a new polyimide film suitable for interlayer dielectric material in microelectronics applications. Microelectronic Journal, 31, 629-634 (2000). 
[2] Hu T., Juuti J., Jantunen H., Vilkman T.: Dielectric properties of BST/polymer composite. Journal of the European Ceramic Society, 27, 3997-4001 (2007).

[3] Jiang L., Liu J., Wu D., Li H., Jin R.: A methodology for the preparation of nanoporous polyimide films with low dielectric constants. Thin Solid Films, 510, 241-246 (2006).

[4] Homma T., Yamaguchi M., Kutsuzawa Y., Otsuka N.: Electrical stability of polyimide siloxane films for interlayer dielectrics in multilevel interconnections. Thin Solid Films, 340, 237-241 (1999).

[5] Maier G.: Low dielectric constant polymers for microelectronics. Progress in Polymer Science, 26, 3-65 (2001).

[6] Lin R-H., Lu W-H., Lin C-W.: Cure reactions in the blend of cyanate ester with maleimide. Polymer, 45, 4423-4435 (2004).

[7] Hwang H-J., Wang C-S.: Thermal behavior and properties of naphthalene containing bismaleimide-triazine resins. Journal of Applied Polymer Science, 68, 1199_ 1207 (1998).

[8] Shieh J-Y., Hwang H-J., Yang S-P., Wang C-S.:Synthesis and properties of a cyanate ester containing dicyclopentadiene(II). Journal of Polymer Science, Part A: Polymer Chemistry, 43, 671-681 (2005).

[9] Schulze K., Schuldt U., Kahle O., Schulz S. E., Uhlig M., Uhlig C., Dreyer C., Bauer M., Gessner T.: Novel low-k polycyanurates for integrated circuit (IC) metallization. Microelectronic Engineering, 82, 356-361 (2005).

[10] Hwang H-J., Li C-H., Wang C-S.: Dielectric and thermal properties of dicyclopentadiene containing bismaleimide and cyanate ester. Part IV. Polymer, 47, 1291-1299 (2006).

[11] Hamerton I.: Chemistry and technology of cyanate ester resins. Chapman and Hall, London (1994).

[12] Srinivasan S. A., McGrath J. E.: Amorphous phenolphthalein-based poly(arylene ether) modified cyanate ester networks: 1 . Effect of molecular weight and backbone chemistry on morphology and toughenability. Polymer, 39, 2415-2427 (1998).
[13] Chang J. Y., Hong J. L.: Morphology of poly(ether sulfone)-modified polycyanurates. Journal of Polymer Research, 4, 203-211 (1997).

[14] Tao Q., Gan W., Yu Y., Wang M., Tang X., Li S.: Viscoelastic effects on the phase separation in thermoplastics modified cyanate ester resin. Polymer, 45, 3505-3510 (2004).

[15] Fang T., Shimp D. A.: Polycyanate esters: Science and application. Progress in Polymer Science, 20, 61-118 (1995).

[16] Hayashi T., Nakamura H., Suzuki T.: Characterization of the curing behaviour of cyanic ester by a positronannihilation lifetime technique. Polymer, 40, 1053 1056 (1999).

[17] Martin M. D., Ormaetxea M., Harismendy I., Remiro P. M., Mondragon I.: Cure chemo-rheology of mixtures based on epoxy resins and ester cyanates. European Polymer Journal, 35, 57-68 (1999).

[18] Thomason J. L.: Investigation of composite interphase using dynamic mechanical analysis: artifacts and reality. Polymer Composites, 11, 105-113 (1990).

[19] Mallarino S., Chailan J. F., Vernet J. L.: Glass fibre sizing effect on dynamic mechanical properties of cyanate ester composites I. Single frequency investigations. European Polymer Journal, 41, 1804-1811 (2005).

[20] Komalan C., George K. E., Kumar P. A. S., Varughese K. T., Thomas S.: Dynamic mechanical analysis of binary and ternary polymer blends based on nylon copolymer/EPDM rubber and EPM grafted maleic anhydride compatibilizer. Express Polymer Letters, 1, 641-653 (2007).

[21] Ashida M., Noguchi T., Mashimo S.: Effect of matrix's type on the dynamic properties for short fiber-elastomer composite. Journal of Applied Polymer Science, 30, 1011-1021 (1985).

[22] Dong S., Gauvin R.: Application of dynamic mechanical analysis for the study of the interfacial region in carbon fiber/epoxy materials. Polymer Composites, 14, 414-420 (1993). 